\title{
Bilingual Education for STEM Achievement: A Comparison of the Nigerian and Texas Bilingual Education Programs
}

\author{
Catherine Omole, Emilia Ugwu \\ Abubakar Tatari Ali Polytechnic, Bauchi, Nigeria \\ Northeastern University, Boston, MA USA
}

\begin{abstract}
The paper is aimed at comparing STEM educational outcomes of Nigerian students who are struggling with low English proficiency (LEP) while also learning Science, Technology, Engineering and Mathematics (STEM) subjects to Texas LEP students, who are often enrolled in Bilingual Education Programs (BEP). In Texas, Bilingual Education and English as a second language programs were implemented to meet the needs of LEP students, whereas in Nigeria, such special programs are not fully developed. Globally, Bilingual Education programs are often provided to indigenous and immigrant LEP students. Texas LEP students' Mathematics, English and Science achievement will be compared to Nigerian students' scores to determine how each group of students have fared under both national policies: US NCLB (No child left behind) act of 2001 and UBE (Universal basic Education) Scheme of 1999. Recommendations will be made from the conclusions drawn
\end{abstract}

\section{Introduction}

The "No Child Left behind Act of 2001" (NCLB) legislation requires schools to focus attention on the academic achievement of traditionally under-served students by mandating local and regional education agencies and their schools/districts to provide programs for enhancing the academic achievement of low-income and minority students who are perennially lower performing and often fail to meet set standards [3]. In essence, NCLB was implemented with the aims of closing achievement gaps between social classes and racial groups and improving the educational outcomes of all US children $[15 ; 4 ; 17]$. NCLB mandates that students take several standardized test, in order to measure their academic achievements throughout the period of their K-12 studies. One of such requirements is annual math and reading testing in grades 3 to 8 as well as in high school [15]. Beginning with the 2007 2008 school years, states were also required to add science as a subject to be tested three times, once during each of three-time frames: grades 3-5, 6-9 and 10-12 [15], [16].
Additionally, schools under NCLB, are required to make Adequate Yearly Progress (AYP) towards proficiency and are subject to certain consequences if they do not reach their targets [15]. If a school has not reached AYP for two consecutive years it is categorized as "needs improvement" and its students must be given the choice to transfer to another public school in the district [16]. Similarly, if a school does not meet AYP targets for more than three years, students from low-income families must be offered supplemental educational services such as tutoring [15], [16]. Furthermore, schools that continue to miss their AYP targets for five consecutive years are subject to being restructured, which may entail hiring new teachers and administrators and implementing curriculum changes [8]. These school improvement measures under NCLB are intended to ensure that low-performing schools are given the attention and resources they need to improve [15].

\section{Universal Basic Education}

The Education for all by the year 2015 (EFA) was one of the most recent Education declarations made in the year 2000 in Dakar which made most African countries to embrace it as a tool for empowerment. In 1990 the Jometian declaration in the World Education conference was Education for all by the year 2003 [2].

In Nigeria, the Universal Primary Education (UPE), which includes 6 years basic education at the primary level was initially introduced in 1976. Children from the age of six were encouraged to go to school, leading to increased primary school enrollment from 6 million to 12 million by the mideighties. Although a positive development, higher student enrolment led to several unexpected problems including insufficient infrastructure, insufficient funding, inadequate teacher preparation amongst others, severely affecting the success of the UPE scheme [9]. As a result of this failure, the UPE scheme was re- evaluated and re-launched and the UBE (Universal Basic Education) was introduced by the then president, Gen Olusegun Obasanjo in 1999. The UBE scheme mandates six years of primary education and three years of the junior secondary school. 
By 2004, the National assembly passed a bill that enacted compulsory and free Universal Basic Education for every child of primary and secondary school age. The principal objective of UBE is to provide quality education to Nigeria's citizens, through the provision of a free education for the Nigerian child of school going age. UBE is also aimed at reducing the dropout rate of school age children. Indeed, UBE focuses on catering to the educational needs of young persons through the acquisition of the literacy, numeracy, communicative, and life skills. Furthermore, the training of adolescents, youths and the nomadic population, who lack a formal education are some of the loft goals of the UBE policy. The Act provides three sources of funding for the implementation of the UBE, which are Federal Government Grant of not less than $2 \%$ of its consolidated revenue fund (funds or contributions in the form of Federal Guaranteed Credits and local or international donor grants), State and the Local Governments. The State government can only benefit from the Federal Government block grant meant for the implementation of the UBE if it can contribute at least $50 \%$ of the total cost of the project (18). This is to ensure the state's commitment towards the project. Parents who fail to send their children and wards to school are to be sanctioned and this is a measure to ensure compliance. The project provides free textbooks in core subjects as well as abolishes tuition at the primary school and at the junior secondary school levels to ensure that poverty issues are addressed, and low-income earners are not left out of the programme. From the various objectives of the UBE, the child should have a continuous, uninterrupted stretch of education for 9 years from primary school to the 3years of the junior secondary school. No entrance examination is expected for transition from the primary to the junior secondary school level. Apart from this, the UBE scheme plans on catering for the adults who have been out of school before they acquired the basic skills needed for life-long learning in form of non-formal programmes. So, the UBE programme is planned in such as to provide non-formal skills and training for youths who have not had the benefit of formal education (18). The UBE scheme has therefore changed the education system from the previous 6,3 , 3, 4 system to $9,3,4$ system.

However, an attempt was made by the UBE scheme to empower teachers with the necessary skills to teach in the mother tongue by organizing a Teacher Professional Programme (TPSP) in 2003. The cluster in-service training and mentoring programme aimed at facilitating a process where they would become creative in a problem solving, production of teaching and learning materials, and preparation of lesson plans and classroom management. The emphasis then was the use of mother tongue as a medium of instruction in primaries $1-3$ in the three core subjects namely; Mathematics, Social Studies and primary science while English was taught as a school subject. For the purpose of the project, nineteen states out of the 36 states of the federation were involved; One Local Government Education Area (LGEA) was selected from each of the 19 states, making a total of 19 LGA'S that was used for the project.

The findings revealed that the pupils learnt better in their mother tongue than when English was being used as a medium of instruction. The project was also an eye opener for teachers, parents and the government; yet Nigerian language policy particularly at the basic level has not been properly implemented (19). More attention needs to be paid to low English proficient Nigerian students with the supplementary educational programs they need, to overcome their English language challenges [10].

Regardless of the shortcomings of the UBE, the NCLB act of 2001 and the 2004 Act of the UBE appear to have a common goal, which is that of improving all aspects of the quality of education that students receive. Both policies are also aimed at ensuring that quality educational programs are provided to all students, so that recognized and measurable learning outcomes are achieved in literacy, numeracy and essential life skills.

\section{Bilingual Education in Texas and Nigeria}

Bilingualism is commonly defined as the use of at least two languages by an individual. However, proficiency in the languages may depend on the exposure and the frequency of use of each language. A student with limited English language proficiency is a student whose primary language is other than English and whose English language skills are such that the student may have difficulty performing ordinary class work in English. The Texas bilingual educational system offers LEP students the opportunity to learn in their mother tongue, while learning English as a second language [15]. This has become necessary due to the fast-growing immigrant population, of which a significant percentage need this assistance [14]. Nigeria on the other hand, is a largely multi-ethnicity over 250 ethnic groups, who speak up to 500 distinct languages and dialects. In Nigeria, the three major languages being are Igbo, Hausa-Fulani and Yoruba. Given the vast array of languages and dialects being spoken, in Nigeria, a universally spoken language or lingua franca became absolutely necessary in order to ease communication. English language is the official language of communication in Nigeria, hence education is carried out primarily in English. Bauchi State in North Eastern Nigeria alone has 55 major tribes from the tribal groups in the state including 
Badawa, Bolewa, Butawa, Fa'awa, Fulani, Gerawa, Hausa, Jarawa, Kanuri, Karekare, Savawa, Wariawa and Zulawa.

Regardless of the differences between the two regions being compared, the main issue is that in both situations, educators are faced with the challenge of educating students who are not fully proficient in English language [14], [15]. Bilingual Education in Texas dates back as far as 1968 and has been undergoing changes and exploring various methods of implementation with time. Nigeria has no properly structured programs, designed to specifically provide Bilingual Education to its students, majority of whom are LEP and implementation of existing policies are poor at best. The language provisions of the National Policy on Education (2004) of the Federal Republic of Nigeria states that the medium of instruction at pre-primary and lower primary classes should be the mother tongue or the language of the immediate community, with transition to English in upper primary classes. Nigerian languages are to be taught as subjects in all primary and secondary classes. The policy also provides that Government would develop the orthography of many more Nigerian languages and also produce textbooks in Nigerian languages. No doubt effective language planning is crucial to the success of primary education in a multi-lingual setting, where the language spoken at home (mother tongue) is different from that used in the school. A clear-cut period is not stated as to when the facilitation should change from the mother tongue to English. At present, we cannot really pinpoint the medium of instruction at the primary school level. The sudden shift from mother tongue to English which is to be affected in primary four is too abrupt as the pupils are not likely to be sufficiently prepared for the change and this will affect the child's performance in all subjects. This is a worrisome issue that has to be addressed. However, implementation of these language policies has not been effective due to multiple problems identified by Ateequ [13] as:

"Multilingual states finding it difficult to cater for numerous languages, some of which have only few speakers. Secondly, urban areas often have classes which contain a mixture of children from different ethno-linguist groups. This makes the language of teaching difficult to pinpoint. Again, apart from the three main languages - Hausa, Igbo and Yoruba most of the 500 Nigerian languages lack orthographies, textbooks, approved curriculum and trained teachers. There is generally a negative attitude to indigenous languages by parents, pupils, students and school authorities alike. Indigenous languages suffer poor funding and lack overall support from the Government".
Robin and Collier $[11 ; 12]$ categorized various US $\mathrm{Bi}-/$ multilingual Education programs for LEP students. These include Bilingual, Submersion, English as a Second Language (ESL) and Immersion programs. Each of these programs presents information to students in more than one language, but the degree to which each language is used in classroom instruction varies in each case. In Bilingual education, whether one way or two-way, instruction occurs in both the English language and the native language spoken by LEP students. English as a Second Language (ESL) programs on the other hand place LEP students in English-only classrooms for part of the day, and allows them to spend the rest of their time with a trained ESL instructor, where they receive individual and concentrated English language instruction. In Submersion, the language of instruction for LEP students is in English, regardless of English proficiency. Conversely, in Immersion programs, students are instructed in a foreign language for the entire school day. Immersion programs differ from submersion programs in that immersion is usually designed to teach a second language to English proficient students. These programs tend to be very effective in fostering bilingualism in its students. One of these educational programmes above would be very useful in tackling the Nigerian pre- primary / primary mother tongue to English language transition issues.

\section{Supporting Stem Education}

Supporting STEM Education has become a necessity in the world of today. STEM education, an acronym for Science, Technology, Engineering and Mathematics Education is very fundamental for nurturing any meaningful scientific and technological breakthrough. This programme was started by Judith A. Ramaley, the former director of the National Science Foundation's education and human-resources division. The aim of Stem education should not only be to teach science content but also to foster creativity, inquisitiveness, improve cognitive skills, and improving understanding and appreciation of the processes of scientific investigation. This approach to education is designed to revolutionize the teaching of subject areas such as mathematics and science by incorporating technology and engineering into regular curriculum by creating a "meta-discipline." It encourages a curriculum that is driven by problem-solving, discovery, exploratory learning, and requires students to be actively engaged in situations in order to find solutions. How can all these be achieved if proper communication is not established between the teacher and the student? Quite a number of technicians who have acquired their skills from the apprenticeship schemes could have had more breakthroughs if only they were exposed to some 
formal education were the fundamental knowledge is acquired. Bilingual education is a good platform to Provide experiences for students to develop functional understanding. It can be planned is such a way as to lay emphasis on students' understanding of science concepts and ability to apply these concepts to new situations. However, in the Nigerian situation, a lot of Investment in training and mentoring of instructors, both in STEM education and the language of instruction is very important and crucial.

\section{Competencies required of a Bilingual Teacher}

The bilingual teacher should be able to plan instruction in both languages. He has to be able to read and write in both languages and also be able to communicate orally in both languages; with the students and the family members of the students, if the need arises.

Providing a multicultural learning environment is one of the duties of the bilingual teacher. He must show respect for language differences and address the cognitive needs of the bilingual learner. He should be able to modify the teaching materials to meet the needs of the learner, e.g. by forming realistic behavioural and performance objectives for each lesson and workable educational evaluation techniques.

One point of note is that in a bilingual class e.g. in Nigeria, English language is identified as the second language, and so the teacher has to consider a lot of factors that that might be affecting teaching, e.g.: the environment, age, home, individual differences, etc. A lot of linguistic concepts will come into play. All content areas are included in the teaching, so the teacher has to plan experiences that are meaningful to be able to promote learning. Variation of strategy and variation of teaching resources will come into play.

Finally, commitment and dedication on the part of the teacher is very important as successes recorded are always a credit to the teacher.

\section{Nigerian Peculiarity}

In providing educational facilities, governments may thus be faced with a conflict in the use of resources, whether to promote primary schooling in areas which have been relatively neglected (and where demands may still not be strong) or whether to place more emphasis on building up technical and other kinds of higher education for higher-level skills; in other words, provision of greater equality of opportunity to press for efficiency in meeting more pressing and demmanding manpower needs.

Uncontrollable and unchecked population growth is a worrisome issue that is of growing concern to the
Nigerian government. The country's leadership is apparently becoming more aware of the need to initiate decisive measures to control the country's population which has been growing continuously. Nigeria's current population projection as at July this year is about 171 million and the population is growing at an alarming rate of 3.2 per cent, according to figures obtained from the National Population Commission (NPC). No meaningful planning is possible without dependable data and statistics. Nigeria has never supported birth control officially, either through a policy or a law, owing to its controversial nature and this applies to many countries of the world. In a nation where the population is unchecked and having no dependable statistics, how does one plan for adequate resources to support education of its youths? Providing enough trained teachers to implement for the bilingual education is one issue, and adequate supporting facilities like developing the textbooks and making them available to all is another for an ever-growing population.

\section{Research Question}

How does the academic achievement of Texas LEP students compare to those of their Nigerian counterparts?

\subsection{Comparative Analysis of Texas LEP and Nigerian students' Mathematics, English and Science achievement}

A comparative analysis of the Mathematics, Reading and Science achievement of Texas LEP students with those of Nigerian students has been carried out and will be discussed the following paragraphs. For the purpose of this paper, student achievement data from Nigeria is available for 20062010. A comparison of the academic achievements of Nigerian students, with those of Texas LEP students has been presented in the subsequent plots. An analysis of the plots shows that Texas LEP student achievement is consistently higher than those of their Nigerian counterparts in all subjects reviewed. What is observable from these plots is that after the implementation of NCLB, Texas LEP student performance as a whole showed a gradual improvement in the years following so that in general, by the end of 2008, the number of Texas LEP students passing had increased by six percentage points for Math, ten percentage points for Reading and at least seven percentage points for science. 


\subsection{Mathematics}

For Mathematics, figure 1 shows that between $10-30 \%$ more Texas LEP students passed mathematics compared to their Nigerian counterparts. Whereas, only $40-57 \%$ of Nigerian students passed mathematics in the years from 20062010. More Texas LEP students (58-74\%) performed at or above acceptable standards [14], [15]. It is important to note that mathematics is a foundation subject in which students' performance has to be continually checked and interventions for better performance looked into.

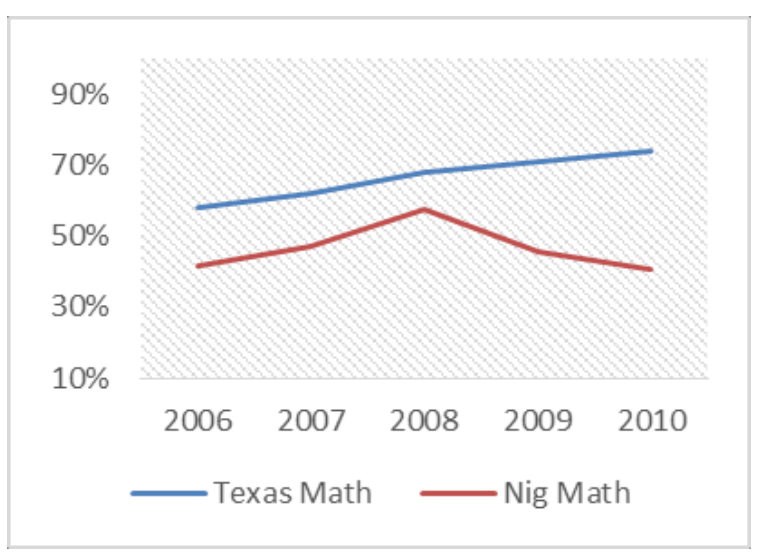

Figure 1. Texas LEP Math vs. Nigeria (Math, 2006-2010)

\subsection{English/Reading}

Similarly, for English language, Figure 2 shows that $16-30 \%$ more Texas LEP students passed English language than did Nigerian students who tested in the same period. Furthermore, although Nigerian students' achievement in English improved by $24 \%$ during the study period, they remained far below the Texas LEP best performance of $73 \%$ of students passing in 2010 .

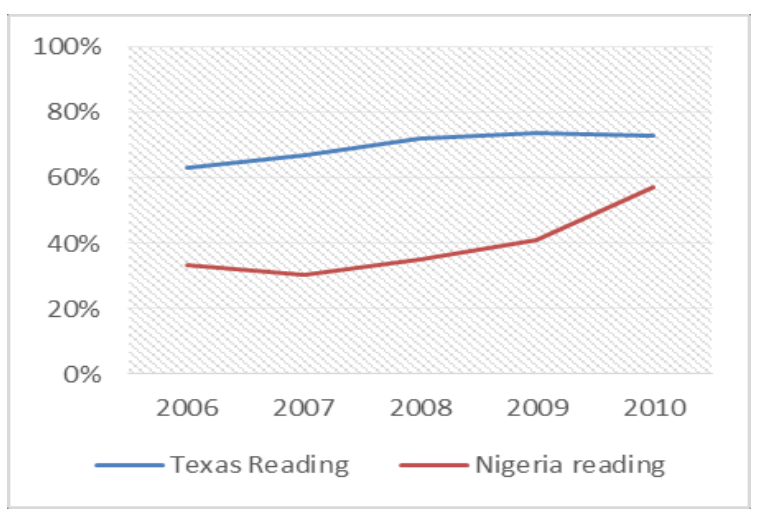

Figure 2. Texas LEP vs. Nigeria

(Reading, 2006-2010)

\subsection{Science}

In addition, Figure 3 shows that in the study period, Nigerian students' academic achievement stayed mostly lower than those of Texas LEP students and did not experience much improvement at all. Although Texas LEP students' achievement improved by $22 \%$ points from 2006-2010, those of the Nigerian Students only grew by $3 \%$ in the same period.

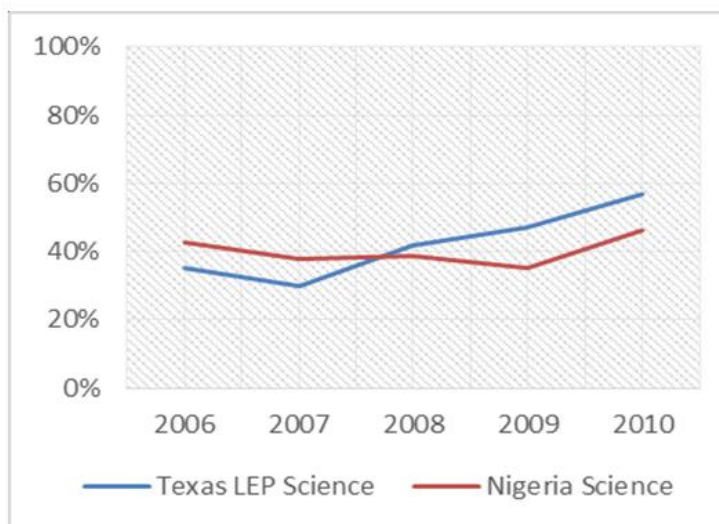

Figure 3. Texas LEP Vs NIGERIA

(Science, 2006-2010)

\section{Challenges}

To ensure effective achievement of the core objectives of bilingual education, one of the major challenges is in the human resources, where by enough competent teachers be trained to teach. Curriculum materials be developed, which include reading materials and teaching materials for the subjects to be taught. Policy implementation is another issue that has to be taken seriously. Well planned programmes can only yield results when proper implementation strategies are in place. Monitoring bodies should be set up to ensure quality delivery. In multi lingual countries, serious decisions are to be made as to the type of bilingual education that will suit their existing situation.

\section{Recommendations and Conclusions}

One of the general objectives of the Bilingual education system is to help sustain the language and culture of the student while trying to pursue an education. The school is to establish communication with the child to make learning easier and interesting, so that concepts are better understood to empower them with skills and knowledge to further influence our lives positively. Because of the multilingual nature of Nigeria, English is the official language and the language of the media; it is not 
possible for Nigeria to wish away English language, more so because it is a major linguistic mode that connects the diverse ethnic groups within the country. Nevertheless, our languages cannot be allowed to die. People who appreciate culture still prefer having communication, and if possible, learning in their language and maintaining their culture. The Texas case is a little different from that of Nigeria. The Texas bilingual educational system offers LEP students the opportunity to learn in their mother tongue, while learning English as a second language [15]. This has become necessary due to the fast-growing immigrant population, of which a significant percentage need this assistance. The immigrant population are also beneficiaries of this system of education.

In a developing Nation like Nigeria, effective teaching and learning processes are essential, so that students will further be encouraged to study STEM subjects which will lead to future carriers in STEM fields. Stem Education also prepares the students for successful employment, enables them to be competent and apply technical and sophisticated skills for the development of the society. Plots presented in this study shows that Texas LEP students perform significantly better than the Nigerian students in reading, mathematics and science. Amongst other factors, effective communication for better understanding is quite fundamental. Student centered bilingual education programs should be created in Nigeria and properly structured so that students can benefit fully. Mastery of basic skills in the mother tongue can be carefully structured and a sequential mastery of English language skills be run alongside, in which skills like reading, writing and listening will be emphasized. All the subjects in the curriculum will be taught in a like manner as this will help facilitate translation to English language. Also, English speaking students should be encouraged by their parents to learn other languages so as to be proficient in more than one language. It is also important to note that only a few indigenous Nigerian languages are developed enough to be taught. LEP schools should be identified so that student centered bilingual education programs in the appropriate indigenous languages can be provided. School evaluations should be carried out at defined intervals in order to improve failing schools or copy what may be working for more successful schools. Due to the multilingual nature of the country and few developed orthographies, the bilingual program can initially be restricted to English and any of the three main languages spoken in Nigeria, which are Hausa, Yoruba and Igbo. The population issues and adequate data base is very important for proper planning and implementation of any programme at any level.

The most important competence expected of a bilingual teacher should be the ability to plan instruction in both languages. He has to be able to read and write in English and the second subject and also be able to communicate orally in both languages; with his students.

\section{References}

[1] A. O. Jaieoba Journal of African and American Studies, Vol. V1 No. 1, 2007, pp 48-58

[2] S. Akinyemi, A. Olorunfemi \& O. I Bassey. Funding Universal Basic education in a Depressed Economy. Pakistan Journal of Social Sciences. Vol. 7 No. 2. 85-89.

[3] R. Balfanz, Can the American high school become an avenue of advancement for all? The future of children, 19(1), 2009, 17-37.

[4] 107th Congress. Public Law 107-110, JAN 8, 2002. 115 STAT. 1425 (page 1425 -2094). [PDF Document]. Retrieved from http://www2.ed.gov/ policy/elsec/leg/esea02/107-110.pdf. (Access date: 14 March 2015).

[5] P. E. Peterson. A lens that distorts: NCLB's faulty way of measuring school quality. Education Next, 7(4).

[6] U.S. Department of Education. Developing Programs for English Language Learners. Retrieved on December 13, 2009 from http://www.ed.gov/abou t/offices/list/ocr/ell/glossary.html\#lau. (Access date: 11 January 2016).

[7] USDE, United States Department of Education. Choice and Supplemental Educational Services Frequently Asked Questions. Retrieved on May 27, 2015 from http://www.ed.gov/parents/schools/choice /choice.html\#6. (Access date: 8 March 2016).

[8] J, Jennings \& D.S. Rentner, NCLB: Ten big effects. PhiDelta Kappa, 88(2), 2006. 110-113.

[9] J. O. Ogunsanmi \& F. O. Ibimiluyi. From the Universal Primary Education (UPE) to Universal Basic Education (UBE) Implications for counseling in Primary and Junior Sec Schools in Nigeria. International journal of Psychology and Counseling. Vol 6(7) 2014, pp. 89-93. http://www.academicjournals.org/IJPC

[14] Texas Education Agency. Adaptations for several populations subchapter bb. Commissioners rules concerning state plans for Educating English language learners. 2011, Retrieved from http://ritter. teastate.tx.us/rules/tae/chapter089/ch089bb.html. (Access date: 9 November 2016). 
[15] E. U. Ugwu, "Changes in Texas English language learners' academic achievement scores after No Child Left Behind" (2014). Education Doctoral Theses. Paper155. http://hdl.handle.net/2047/d20004 820.

[16] USDE, United States Department of Education. United States Supplemental educational services frequently Asked Questions, 2004.

[17] USDE, United States Department of Education. Improving the academic achievement of the disadvantaged, 2010.

[18] S.O. Labo-Popoola, A.A. Bello and F.A. Atanda Universal Basic Education in Nigeria: Challenges and Way Forward Pakistan Journal of social Sciences Vol, 6, no.5.252-259,2009.

[19] F.Ojetunde, A critical Implementation of the language policy at the pre-pimary and the primary levels. Journal of Education and practice ISSN 22221735 paper, ISSN 2222-288x online vol.3 No,16 2012. 